\section{IN THE NEWS}

How tickled am I?

When we ponder the really

big questions in

neuroscience, it's unlikely

that the first one that springs to mind is "Why can't I tickle myself?" Yet researchers at the University of Wales in Swansea claim that the answer to this question could have important ramifications for the study of consciousness.

The research team, led by Dr Mark Blagrove, used a

"2-foot long, electronicallycontrolled 'tickler"'

(icwales.icnetwork.co.uk,

5 April 2004) to test the ability of volunteers to tickle

themselves when they were fully awake, or had just woken from rapid eye movement (REM) or non-dreaming sleep. They found that if the volunteers used the machine to tickle themselves just as they were waking from REM sleep, the sensation was as intense as if someone else was doing the tickling, but this was not the case if they were awake or had just woken from non-dreaming sleep.

Blagrove compares the dream state to the

hallucinatory state in schizophrenia: "People with schizophrenia can successfully tickle

themselves because they produce hallucinations, but think that what they see is real ... not actually produced by them. REM sleep allows you to believe that the events of the dream are real, that you are not producing them, and this .... carries over for a few minutes when you are awake" (BBC News Online, 5 April).

So, other than giving hope to people who have a

burning desire to be able to tickle themselves, what are the implications of this research? Blagrove says: "It is quite an important thing in terms of when do people feel in control of what they are doing, and when do they think things are being done to them. It is all to do with whether you can monitor what you are doing to yourself" (BBC News Online).

Heather Wood

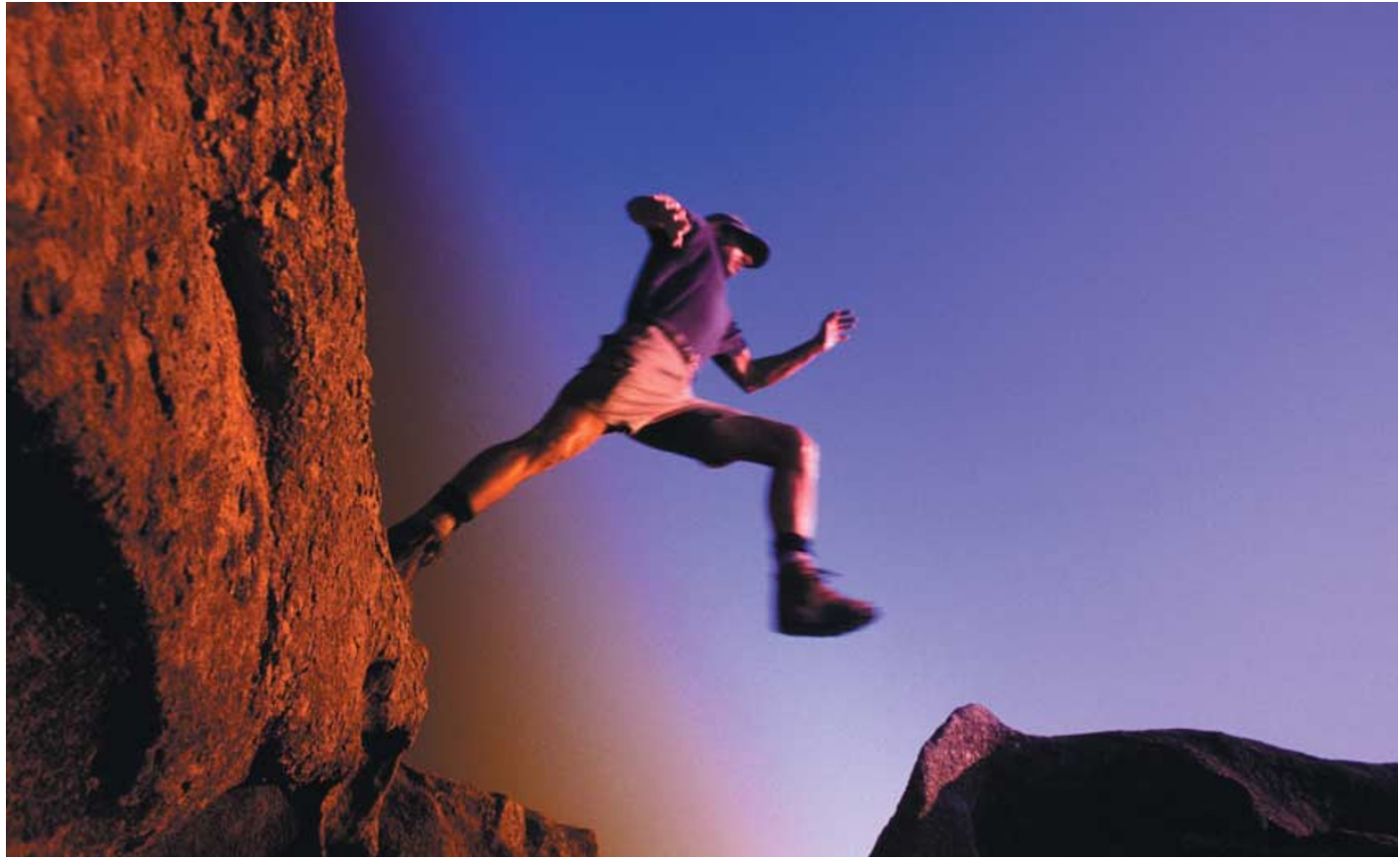

PRIONS

\title{
Proteins go it alone
}

Two recent papers published in Nature provide the strongest evidence yet to support the protein-only hypothesis for the transmission of prion diseases. In addition, these studies - one by King and Diaz-Avalos, and the other by Tanaka and colleagues - confirm that distinct 'strains' of prion arise in the absence of genetic alterations owing to differences in protein conformation.

Although it is generally accepted that proteins are the sole infectious agents in prion diseases, this has been difficult to prove. In the new studies, the authors used a yeast system to demonstrate this principle. Sup35 is a Saccharomyces cereviseae prion that is required in normal cells for the termination of translation. Similar to the events that occur in prion diseases, Sup35 can be converted into an 'infectious' form that can propagate itself and form aggregates known as amyloids. Cells in which this has occurred are known as $\left[\mathrm{PSI}^{+}\right]$cells, and can be distinguished from their normal counterparts, $\left[p s i^{-}\right]$cells, by alterations in their colour under certain conditions. The authors used Escherichia coli to overexpress a region of Sup35 that is sufficient to stimulate amyloid formation and purified aggregates of this protein. Expression in a bacterial system ensured the absence of any virus from the yeast cells that might be responsible for infectivity. They then used novel methods to deliver the aggregates into [ $\left.p s i^{-}\right]$cells and showed that this resulted in conversion to the $\left[\mathrm{PSI}^{+}\right]$state. Protease treatment greatly decreased the infectivity of the aggregates, whereas nuclease treatment had no effect, providing the strongest evidence so far that prion proteins, in the absence of genetic material, are sufficient for infectivity.

Another contentious issue in prion research is the existence of different 'strains' of the same prion protein that vary in their infective properties. How can these distinct characteristics arise if a single protein-only agent is responsible for transmission? Both groups showed that the generation of various conformations of the same protein underlies the existence of different prion strains. In S. cereviseae, several $\left[\mathrm{PSI}^{+}\right]$strains can be distinguished on the basis of differential levels of Sup35 aggregation. Both groups found that when Sup35 aggregates from a specific strain were used to infect $\left[p s i^{-}\right]$ cells, the recipient cells were converted to the $\left[\mathrm{PSI}^{+}\right]$ strain from which the aggregates were derived. They also showed that Sup35 amyloids with distinct conformations are generated in vitro at various temperatures and that these distinct forms induced different infective characteristics when introduced into $\left[p s i^{-}\right]$cells.

So, a prion protein folded in a specific way can induce the stable propagation of that conformation, with different strains being more or less efficient at converting the normal form of the protein. How this conversion takes place at the molecular level will be a key question for future investigation.

Louisa Flintoft, Assistant Editor, Nature Reviews Microbiology

\section{(2) References and links}

ORIGINAL RESEARCH PAPERS King, C.-Y. \& Diaz-Avalos, R. Protein-only transmission of three yeast prion strains. Nature 428, 319-323 (2004) Tanaka, M., Chien, P., Naber, N., Cooke, R. \& Weissman, J. S. Conformational variations in an infectious protein determine prion strain differences. Nature 428, 323-327 (2004) 